\title{
Sealant injectivity through void space conduits to assess remediation of well cement failure
}

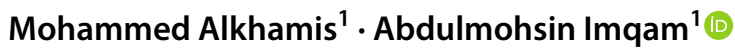

Received: 23 March 2021 / Accepted: 11 June 2021 / Published online: 24 June 2021

(c) The Author(s) 2021

\begin{abstract}
The primary cement of oil and gas wells is prone to fail under downhole conditions. Thus, a remedial operation must be conducted to restore the wellbore integrity and provides zonal isolation. Many types of materials are currently used and/ or have the potential to be employed in wellbore integrity applications, including, but not limited to, conventional Portland cement, microfine and ultrafine cement, thermoset materials, and thermoplastic materials. In this study, several types of materials were selected for evaluation: (1) conventional Portland cement, which is the most widely used in remedial operations in the petroleum industry, (2) polymer resin, which is one of the most recent technologies being applied successfully in the field, (3) polymer solutions, and (4) polymer gel, which is a semisolid material that has shown potential in conformance control applications. This work addresses injectivity and the parameters that affect the injectivity of these materials, which to the authors' best knowledge have not been addressed comprehensively in the literature. The results of this study demonstrate the effects of several factors on the injectivity of the sealants: void size, viscosity of the sealant, injection flow rate, and heterogeneity of the void. The results also promote the use of solids-free sealants, such as epoxy resin, in wellbore remedial operations because epoxy resin behaved like Newtonian fluid and can therefore be injected into very small voids with a minimum pressure requirement.
\end{abstract}

Keywords Well cement failure $\cdot$ Polymer $\cdot$ Epoxy $\cdot$ Injectivity $\cdot$ Rheology $\cdot$ Preformed particle gel

$\begin{array}{ll}\text { Nomenclature } \\ \text { API } & \text { American Petroleum Institute } \\ \text { PPG } & \text { Preformed Particle Gel } \\ \mathrm{NaCl} & \text { Sodium Chloride } \\ \mathrm{Ppm} & \text { Parts per million } \\ \text { DSR } & \text { Dynamic Shear Rheometer } \\ \text { G' } & \text { Storage modulus } \\ \mathrm{Rpm} & \text { Revolution per minute } \\ \mathrm{ml} / \mathrm{min} & \text { Milliliter per minute } \\ \mathrm{psi} & \text { Pounds per square inch } \\ \mathrm{cp} & \text { Centipoise } \\ \mathrm{Pa} & \text { Pascal }\end{array}$

Abdulmohsin Imqam

Missouri University of Science and Technology, Rolla, USA

\section{Introduction}

During the life of oil and gas wells, the wellbore cement is subjected to numerous types of failures, with many causes, as addressed by Alkhamis and Imqam (2021). Failures include, but are not limited to, the formation of micro-annuli between the well cement and its surroundings, cracks and fractures within the cement sheath, and channels that may develop during the hydration process of the cement. The failures may occur due to insufficient mud removal before the cementing operation, improper hydrostatic pressure delivered by the cement slurry during the primary cementing operation, casing expansion and contraction, and/or post-cementing causes, such as high-pressure tests and high-temperature variations during production (Thiercelin et al., 1998; Alkhamis and Imqam, 2018). Whether these failures occurred during drilling and completion, production, or even after abandonment, a remedial cementing job or "secondary cementing" operation is performed to restore the wellbore cement integrity. The well integrity is known as "application of technical, operational, and organizational solutions, to reduce risk of uncontrolled release of formation 
fluids throughout the life cycle of a well" (Norsok D-010, 2013). For this reason, the wellbore cement integrity must be maintained through the life of the well and after abandonment. Prior to any remedial operation, an injectivity test, using solids-free fluids, is conducted to determine some of the parameters required for secondary cementing as this operation requires a careful analysis. This analysis includes estimating the significance of the problem, evaluating the associated risk factors, selecting the proper sealing material, choosing the placement technique, and assessing the economic costs.

Many materials can be used to seal the fluid's pathways, which are created in the wellbores when failures occur, including conventional Portland cement, microfine cement, ultrafine cement, polymer gels, and polymer resins. The advantages and disadvantages of each of these sealing materials are discussed below.

For decades, Portland cement has been employed as the first choice for remedial jobs (Shryock and Slagle, 1968). In a process known as squeeze cementing, the cement slurry is forced into an opening in the casing to fill the voids behind the casing. The cement will then hydrate inside the voids, plugging any pathways for fluid migration. Although, this might sound like an easy process, it is associated with many complications. For example, the process may require more than one squeeze to plug the voids (Sanabria et al., 2016), or it might need a different squeezing technique, such as hesitation squeeze. In addition, this operation is limited by the void size (Jones et al., 2014), as the cement's solid particles may form a bridge in narrow clearances (Davis, 2017). Microfine and ultrafine cement are also limited in penetrating voids less than 300 microns in width (Wasnik et al., 2005). Another limitation is the vulnerability of the cements' thickening time during which it can be affected by contamination (Dahlem et al., 2017). Also, this operation requires casing perforation in general. As alternatives, polymer gels and polymer resins may be used in cement remediation to overcome the limitations of conventional cement.

Polymer gels are mixtures of polymers and crosslinkers that can be combined and optimized to transform from liquids at the surface to semisolids in place. The polymerization may be activated by pressure, temperature, salinity, or acidity. Polymer gels can penetrate small voids, but the 3-D structure of the gel may break down at high temperatures, losing its ability to trap fluids such as water in conformance control applications. Other limitations of polymer gels are their lack of mechanical strength (Wasnik et al., 2005) and bonding properties (Abdulfarraj and Imqam, 2020).

On the other hand, polymer resins, which are mixtures of base resins and hardeners (i.e., "curing agents"), have superior properties, as reported repeatedly in the literature. Polymer resins are defined as "free flowing polymer solutions that can be irreversibly set to hard, rigid solids" (Morris et al., 2012). The exceptional properties of polymer resins vary and include pre-curing (e.g., their tunable rheological behavior) (Alsaihati et al., 2017); surface wetting and adhesion abilities (Brooks et al., 1974; Shaughnessy et al., 1978); the ability to penetrate narrow voids (Todd et al., 2018); tunable density (which can be used for areas with a narrow fracture gradient) (Sanabria et al., 2016); and resistance to contamination (Perez et al., 2017). In addition, polymer resins possess excellent post-curing properties, such as high mechanical strength (Ali et al., 2016; Elyas et al., 2018), high resistance to significant strain (Khanna et al., 2018), and good bonding properties (Genedy et al., 2017). As a bonus, the polymerization reaction of polymer resins forms no by-product during hardening (Muecke, 1974), resulting in very little to no shrinkage. These properties have been also reported by Alkhamis et., (2019).

Selecting the proper sealant depends on the field job itself, meaning there are no general guidelines or rules to be followed in every case. However, there are some materials properties that can help to increase the possibility of a successful remedial operation. This work focuses on estimating the injectivity of several materials and analyzing the main factors that affect the injectivity of these materials, which is a key property that has not received enough attention in the literature on wellbore integrity. In this study, the primary factors affecting the injectivity were studied individually to identify which were major and which were minor. These factors included the type of fluid, void size into which the remedial fluid was injected, viscosity of the fluid, flow rate of the injection, heterogeneity of the void, and effect of the injection on the properties of the injected fluid.

\section{Experimental methodology}

\section{Materials}

\section{Cement}

The cement used in this study was prepared by mixing API class $\mathrm{H}$ cement obtained from Halliburton company with distilled water. The grain size ranged from 10 to 150 microns. The water/cement ratio was 0.38 , as stipulated in API specification 10 A (API, 2010). The mixing was conducted in accordance with the mixing procedure of API RP 10B-2 (API, 2013), in which water was added first to a two-speed, bottom-drive laboratory blender, after which dry cement was added gradually to the blender while mixing at low speed for approximately $15 \mathrm{~s}$. Then, the speed of the blender was increased to high speed for around $35 \mathrm{~s}$. 


\section{Preformed particle gel (PPG)}

LiquiBlock $^{\mathrm{TM}} 40 \mathrm{~K}$, a cross-linked polyacrylic acid/polyacrylamide copolymer particles gel obtained from Emerging Technologies was mixed with $1 \% \mathrm{NaCl}$ brine solution. The dry gel particles were added to the brine solution during mixing with a magnetic stirrer. The solution was then left overnight to ensure full swelling. Next, the swollen particles were sieved and applied in this study as a semisolid material. The dry particle sizes ranged from 420 to 841 microns (20-40 mesh).

\section{Hydrolyzed polyacrylamide polymer (HPAM)}

A commercially available $20 \%$ hydrolyzed polyacrylamide polymer was mixed with distilled water using a magnetic stirrer. The powdered polymer was added slowly to the water while mixing, and the mixing was continued for around $24 \mathrm{~h}$ to obtain a homogenous solution. Three concentrations were used, $0.1 \%$ (1000 ppm), 0.3\% (3000 ppm), and 0.6\% $(6000 \mathrm{ppm})$, with the polymer solutions being solids-free materials.

\section{Epoxy resin}

Epoxy resin was prepared by mixing an epoxy resin with an aromatic hardener at room temperature. The base resin was a diglycidyl ether of bisphenol A (DGEBA) obtained from Miller-Stephenson Chemical Company diluted with cyclohexanedimethanol diglycidyl ether (CHDGE), obtained from the same company. The diluent amount added to the resin was $100 \%$ by resin weight. The selection of this amount was based on a previous study conducted by Alkhamis and Imqam (2019). The aromatic hardener was diethyltoluenediamine (DETDA), obtained from Albemarle Corporation. The diluted DGEBA was accurately weighed into a glass beaker with the appropriate amount of DETDA (52\% by weight of the diluted resin). The sample was stirred thoroughly at which point the curing agent was completely dissolved and a clear homogeneous mixture was obtained.

\section{Rheological measurements}

For the rheological measurements, three types of instruments were used. A dynamic shear rheometer (DSR) with parallel plates system supplied by Anton Paar measured the viscosity of the epoxy resin and the storage modulus ( $\mathrm{G}^{\prime}$ ) of the PPG. A rotational viscometer (model 800) supplied by OFI Testing Equipment, Inc. (OFITE), characterized the viscosity behavior of the cement. A rheometer supplied by Brookfield Ametek, model DV3T assessed the viscosity of the polymer solutions.
To measure the viscosity of the epoxy resin, samples ranging from 0.5 to $1.0 \mathrm{ml}$ of epoxy resin were placed on the lower plate of the instrument, and the upper plate was lowered to maintain a gap of 0.5 to $1.0 \mathrm{~mm}$. The readings were taken in both ascending and descending order in a range from 0.1 1/s to 1000 1/s. To measure the storage modulus of the PPG, a sample of the swollen gel underwent in a similar procedure to the one undergone by the epoxy, but in this test, an oscillatory motion was applied at a frequency of $1 \mathrm{~Hz}$ to estimate the strength of the PPG.

For the cement's viscosity measurements, the cement slurry was mixed and preconditioned at room temperature for $20 \mathrm{~min}$. Then, the slurry was poured into the viscometer cup. The dial readings were taken in both ascending and descending order, with the highest speed being $300 \mathrm{rpm}$ so not to disturb the slurry. The slurry viscosity readings were recorded as the average of the two dial readings at each speed.

For the HPAM viscosities, the solutions were prepared and samples of $8 \mathrm{ml}$ were poured into the cup of the rheometer; readings were taken in both ascending and descending order. The rotational speeds were in the range of 0.1 to $250 \mathrm{rpm}$, with a waiting time of two minutes between each speed. The viscosity values presented in this work are the average values of the readings at each speed. The torque percentages were also recorded at each speed, and any torque value lower than $10 \%$ was removed as recommended by the rheometer's manufacturer.

\section{Injectivity measurements}

Prior to any remedial operation, an injectivity test is performed to set the pressures and flow rates at which remedial fluids can be pumped into leakages zones. This test helps in determining the key parameters for the treatment as well as the major limitations of the operation.

In this study, the experimental setup Fig. 1, consisted of a syringe pump, an accumulator, two pressure transducers, and stainless-steel tubes with various inner diameters (i.e., 0.876, 1.753 , and $4.572 \mathrm{~mm}$ ). These sizes were selected to be less than 0.3875 inches $(9.8425 \mathrm{~mm})$, which was the estimated size for cement channels that were remediated by the use of epoxy resin in the field (Khanna et al., 2018). This setup was prepared to establish the injectivity of several materials that have been employed or have the potential to be used for wellbore integrity applications. The materials included conventional API cement, solids-free polymer solutions, epoxy resin, and semisolid particle gels (PPG).

First, the accumulator was filled with the tested material and the injection began at a low flow rate of $1 \mathrm{ml} / \mathrm{min}$. Then, the flow rate was increased to 2,4 , and $8 \mathrm{ml} / \mathrm{min}$ and the injection pressure and the halfway pressure were recorded

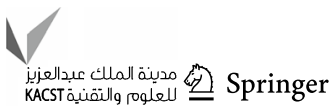


Fig. 1 Illustration of the injectivity setup

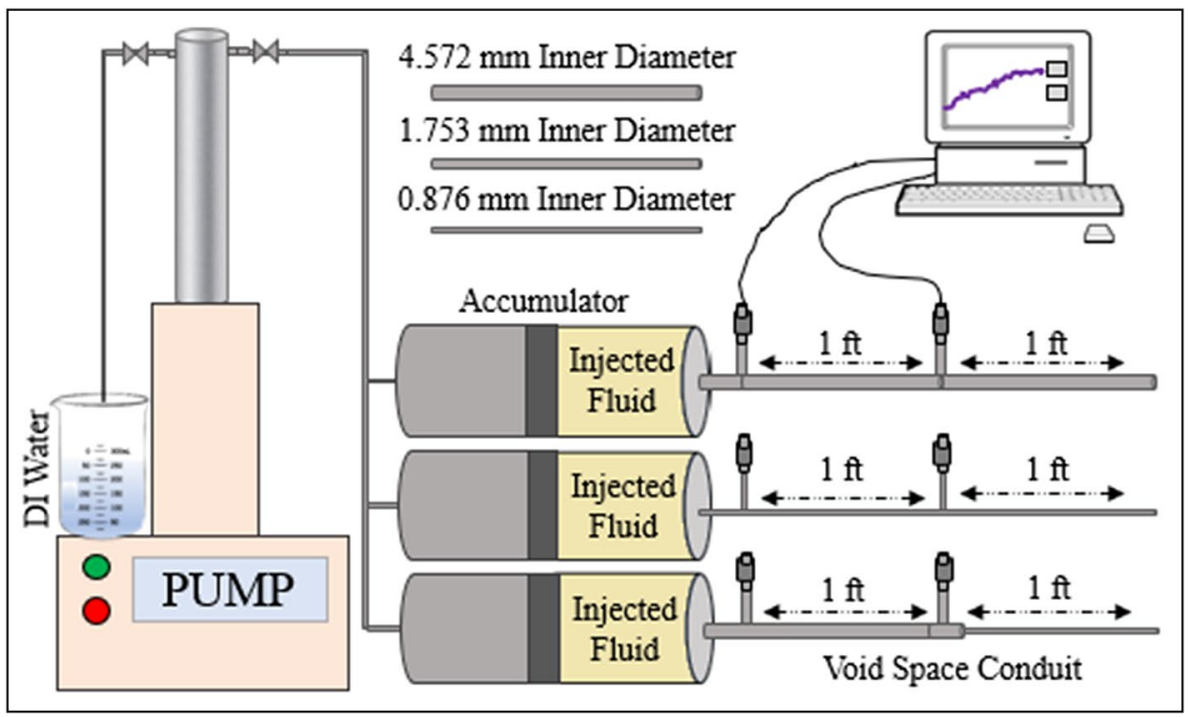

by pressure transducers. The fluids were collected from the outlet to be observed visually and tested using the rheological measurements mentioned above. Then, the injectivity of the fluids was calculated using Eq. 1.

Injectivity $=\frac{\text { Injection Flow Rate }}{\text { Injection Pressure }}$

where the injection flow rate is expressed in $\mathrm{ml} / \mathrm{min}$, the injection pressure is expressed in psi, and the injectivity is expressed in $\mathrm{ml} / \mathrm{psi}$ *min.

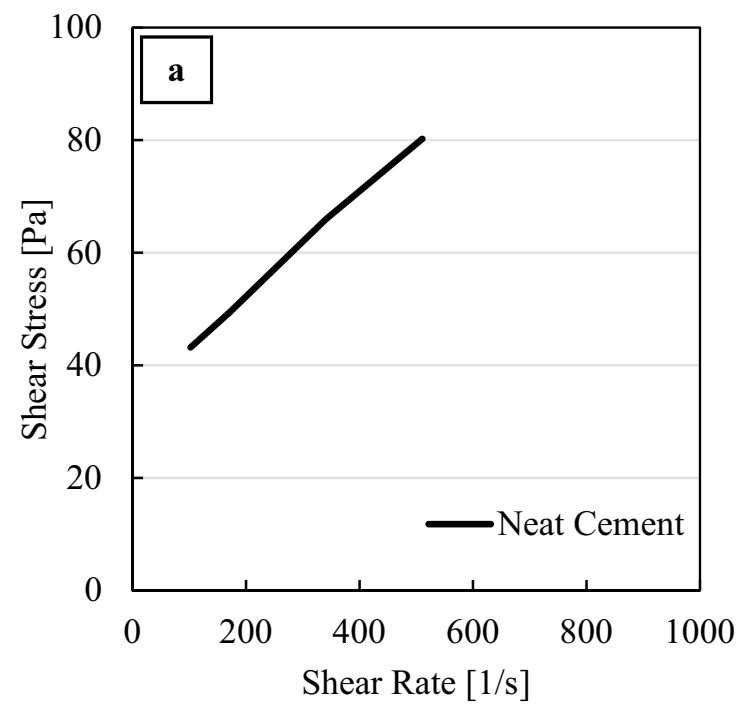

\section{Results and analysis}

\section{Rheological results}

Multiple parameters affect the injectivity of any material, with one of the most significant being its viscosity. In this study, the viscosity of the cement was measured using a rotational viscometer. Figure 2 a shows the viscosity behavior of API cement class H. The cement exhibited a behavior similar to that of Bingham plastic model, which requires a yield stress to initiate flow. On the other hand, the epoxy resin behaved like a Newtonian fluid Fig. 2b, where no stress or only a very small stress was required to initiate flow, and the viscosity was independent of the

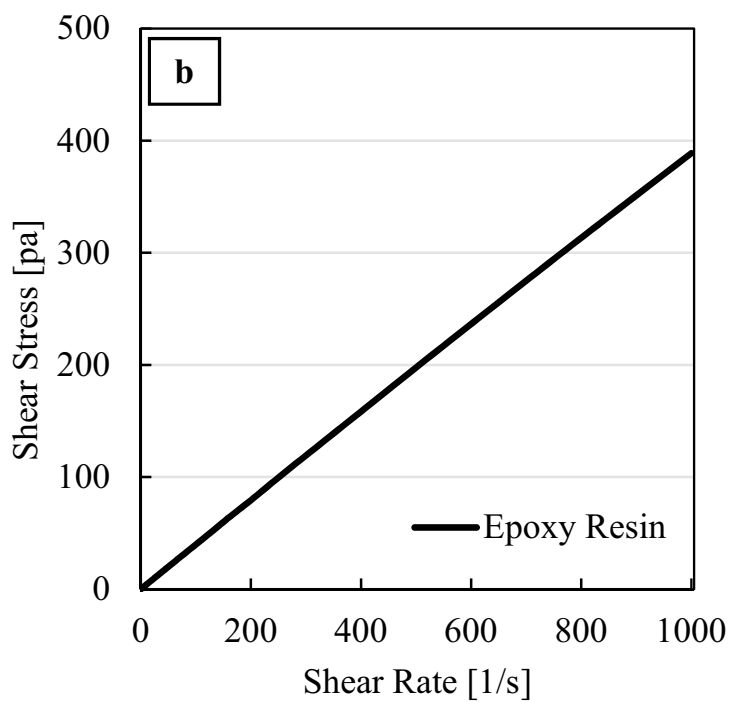

Fig. 2 Viscosity results of $\mathbf{a}$ class $\mathrm{H}$ cement and $\mathbf{b}$ epoxy resin 
shear rate. The viscosity of the epoxy resin was around $400 \mathrm{cp}$. For the PPG, since the material is semisolid, the rheology characterization makes more sense in terms of the storage modulus, which represents the strength of the material. The strength of PPG can be controlled by adjusting the salinity of the brine in which the gel particles are swollen (Imqam et al., 2017). However, the swelling capacity will also be affected. In general, the higher the salinity, the higher the strength and the lower the swelling ratio. In this study, the gel particles were swollen in $1 \mathrm{wt} \% \mathrm{NaCl}$, resulting in a G' of $850 \mathrm{pa}$, estimated using the DSR.

For the HPAM solutions tested in this study, a rotational rheometer with a cup was used. HPAM is a solid-free solution that is widely used in enhanced oil recovery applications. For wellbore integrity applications it can be mixed with an initiator to create a 3-D network to plug cement gaps. In this work, three concentrations of HPAM were studied; $0.1 \%$ (1000 ppm), represented in this paper as low viscous solution (LV); $0.3 \%$ (3000 ppm), represented in this paper as moderately viscous (MV); and 0.6\% (6000 ppm), represented in this paper as highly viscous (HV). Figure 3 illustrates the rheological behavior of the HPAM solutions. The HPAM solutions experienced shear thinning behavior in which the viscosity decreased by increasing the shear rate. Different concentrations were selected to study the effect of the viscosity of the material on its injectivity.

\section{Sealant injectivity results}

The injectivity of the materials tested was measured using the setup in Fig. 1. Several experiments were conducted to better identify and understand the most important factors that affect cement remedial operations and the selection of the proper sealant. These factors include the type of fluid injected, void size into which the remedial fluid is injected, viscosity of the fluid, flow rate of the injection, heterogeneity of the void, and effect of the injection on the properties of the injected fluid.

\section{Effect of the void size on injectivity}

Three void sizes were used, consisting of two-foot tubes with inner diameters of $0.8763 \mathrm{~mm}, 1.753 \mathrm{~mm}$, and $4.572 \mathrm{~mm}$. The fluids' injection pressure and halfway pressure were monitored and recorded. The injectivity of each fluid at various conditions was calculated based on the flow rate used and reaching stable pressure. Figure 4a illustrates the injection pressure of the $0.1 \%$ (1000 ppm) polymer solutions (i.e., LV polymer solution), showing that after approximately $10 \mathrm{~min}$, the solutions reached stable pressure. The pressure increased as the void size decreased. The pressure was around $0.07 \mathrm{psi}$ when the $4.572 \mathrm{~mm}$ void was used and increased to around $2.85 \mathrm{psi}$ when the $0.8763 \mathrm{~mm}$ void was used. Both experiments were run at a flow rate of $1 \mathrm{ml} / \mathrm{min}$. This huge increase in pressure reduced the injectivity by approximately $96.5 \%$ (from 10 to $0.348 \mathrm{ml} / \mathrm{psi}$ *min). There were no changes in the appearance of the solutions before and after the injection, which correlates to the viscosity measurements that will be presented later in this paper. Figure $4 \mathrm{~b}$ shows the injection pressure of PPG vs. time. The void size had a more significant impact on the injectivity of the PPG, increasing the injection pressure from around 2 to 80 psi using a flow rate of $1 \mathrm{ml} / \mathrm{min}$ for both tests. In addition, permanent deformation of the gel particles was

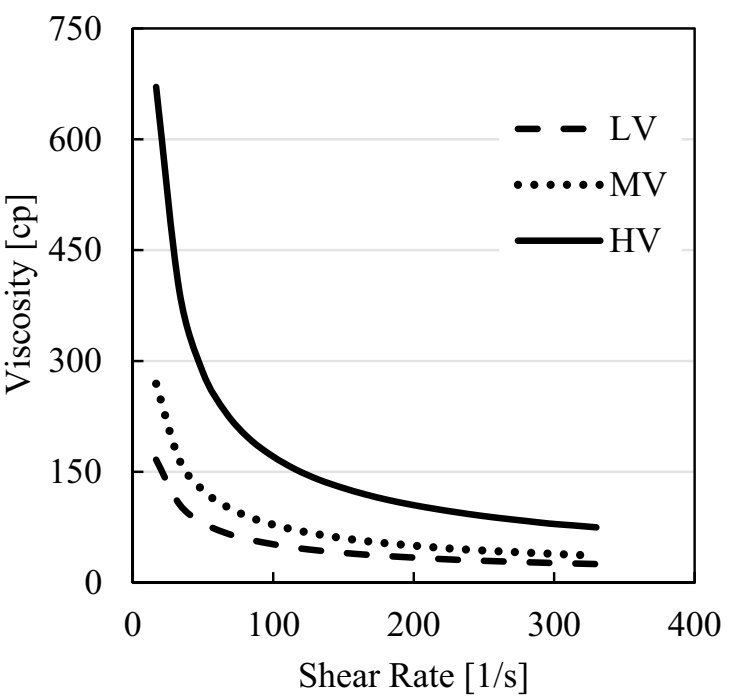

Fig. 3 Viscosity results for HPAM solutions

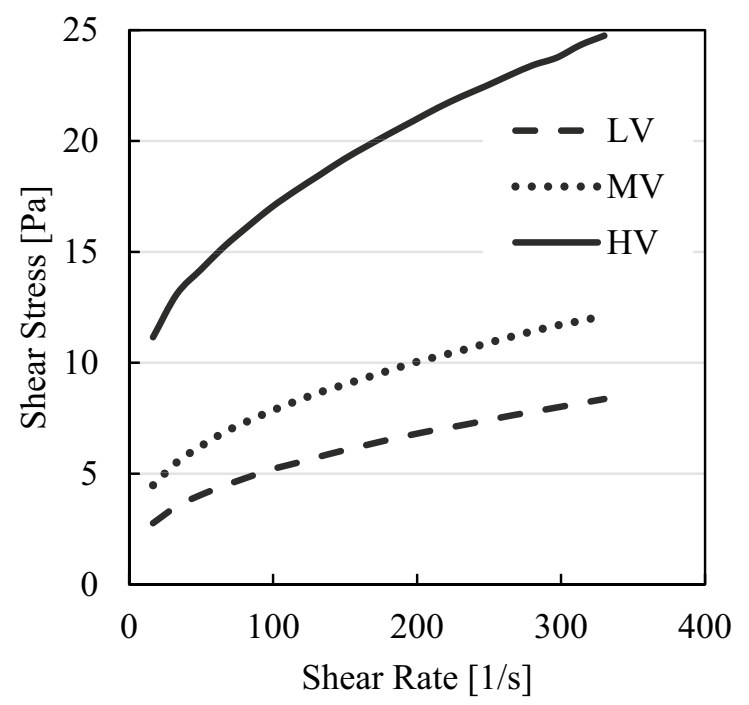




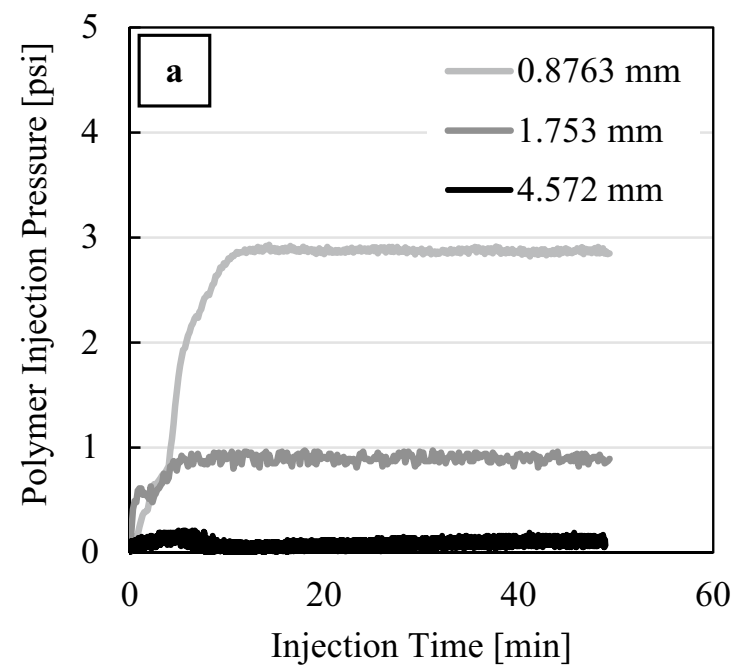

Fig. 4 Effect of the void size on the injectivity of a HPAM, and b PPG

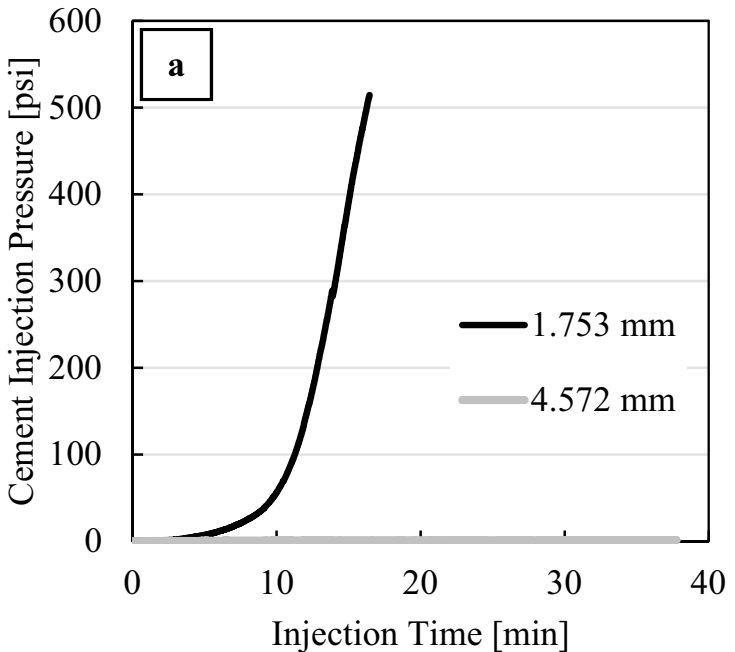

Fig. 5 Effect of the void size on the injectivity of cement

observed at the outlet of the $1.753 \mathrm{~mm}$ void but not in the $4.572 \mathrm{~mm}$ void.

The permanent deformation of the PPG and the great increase in the injection pressure when the $1.753 \mathrm{~mm}$ void was used eliminated the need to use smaller sized void. Conventional Portland cement is the most widely used material for oil and gas wells repairs. However, Portland cement has limitations, and primarily the size of the gaps that the cement can penetrate, as evident in Fig. 5a. With a void size of $4.572 \mathrm{~mm}$, the cement injection pressure was slightly higher than that with LV polymer solution and relatively smaller than with the PPG. In this experiment, the cement showed high injectivity and passed through the void easily. However, when the void size was reduced to $1.753 \mathrm{~mm}$, the cement injection pressure increased
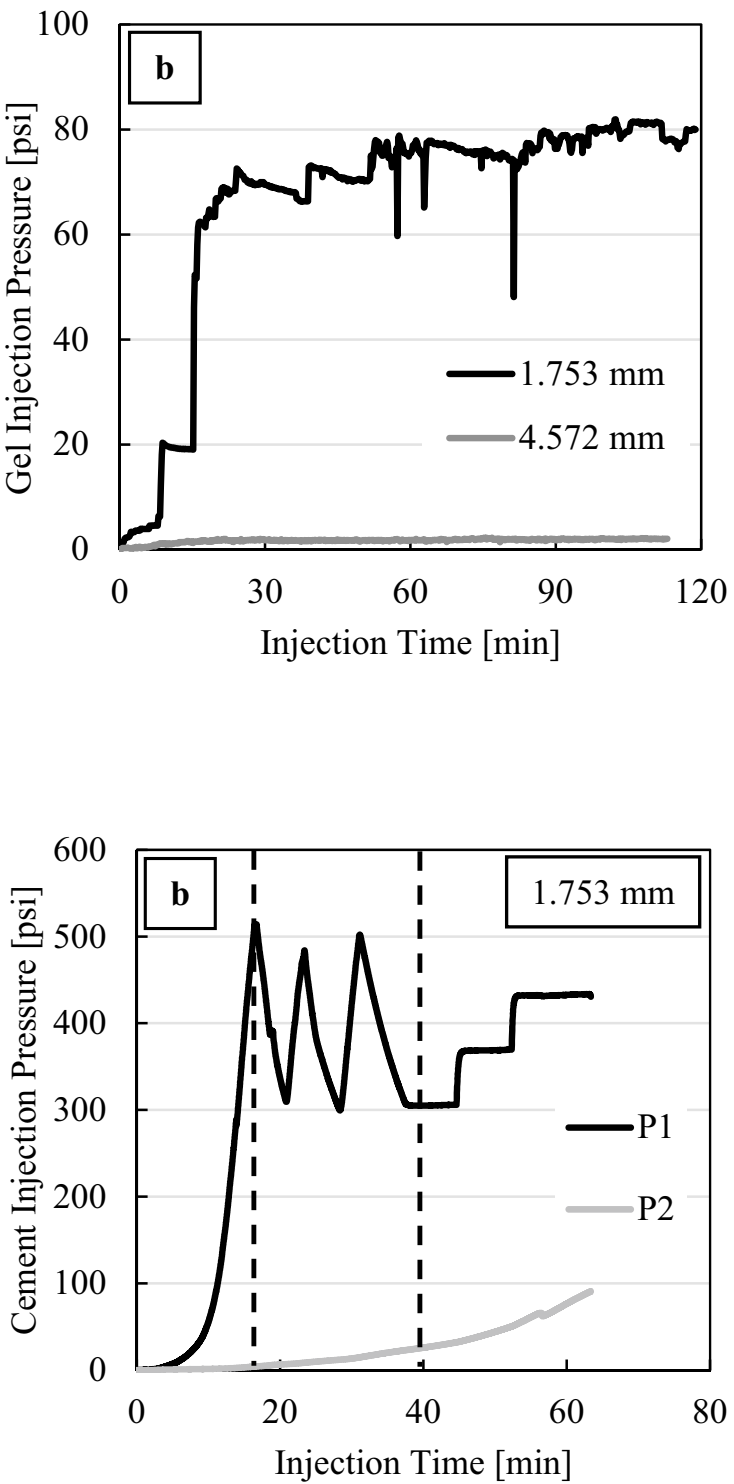

drastically to more than 500 psi. The associated reduction in the injectivity of the cement was near $99.78 \%$. This effect of the void size on the cement injectivity has led the industry to shift or consider shifting to alternative sealants for wellbore remediation operations. In addition, the industry has sought other solutions, such as altering the methods of injecting the remedial sealants. Figure $5 \mathrm{~b}$ demonstrates how using the same void size $(1.753 \mathrm{~mm})$ but switching the injection mode from running squeeze to hesitation squeeze helped to raise the chances of successful cement placement. Lastly, in Fig. 5b, the effect of the constant injection pressure can be seen in the far right section of the graph, which shows that the cement was not able to pass through the first foot to the point where the second pressure recorder was located; however, switching 
the method of injection facilitated the process, as shown in $\mathrm{P}_{2}$ at the 18th minute. Also, the constant injection pressure supported the continual increase in $\mathrm{P}_{2}$, which indicates that the cement was flowing inside the void. At the effluent of the void of these experiments, there were two major observations worth mentioning. First, when using the larger void size $(4.572 \mathrm{~mm})$, the effluent manifested at first as drops of water, followed by cement slurry, then again as a few drops of water, followed again by cement slurry, indicating that the water might have separated from the cement slurry during the injection. This separation can greatly impact the outcome of the remedial operation. Second, during the $1.753 \mathrm{~mm}$ test, there were only a few drops of water, but the cement was able to plug the void.
These changes in the cement fluidity can be overcome by the use of additives, such as fluid loss additives. In this study, only neat cement was injected to reduce the complexity of the tests.

On the other hand, the epoxy showed similar behavior to the HPAM, in terms of injectivity with respect to the void size. Figures 6 a shows the low injection pressure required to force the epoxy into the 1.753 , and $4.572 \mathrm{~mm}$ voids. The injectivities of the epoxy at a flow rate of $1 \mathrm{ml} / \mathrm{min}$ were 0.27 and $10.0 \mathrm{ml} / \mathrm{psi}{ }^{*} \mathrm{~min}$. However, the injectivity reduced to approximately $0.025 \mathrm{ml} / \mathrm{psi}$ *min when $0.8763 \mathrm{~mm}$ void was used (see Fig. 6b), which is due to the high viscosity of the epoxy. This viscosity can be altered using diluents, reactive
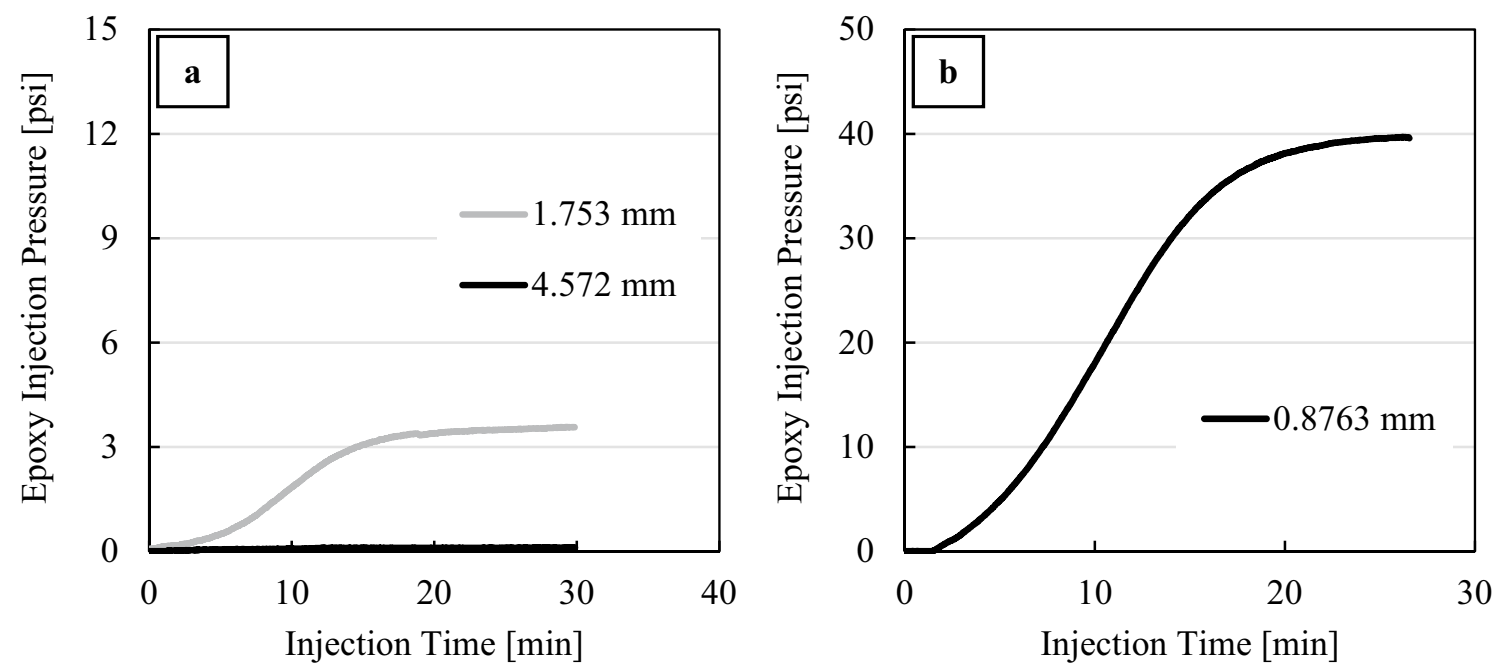

Fig. 6 Effect of the void size on the injectivity of epoxy a 1.753, and $4.572 \mathrm{~mm}$ voids, and $\mathbf{b} 0.8763 \mathrm{~mm}$ void
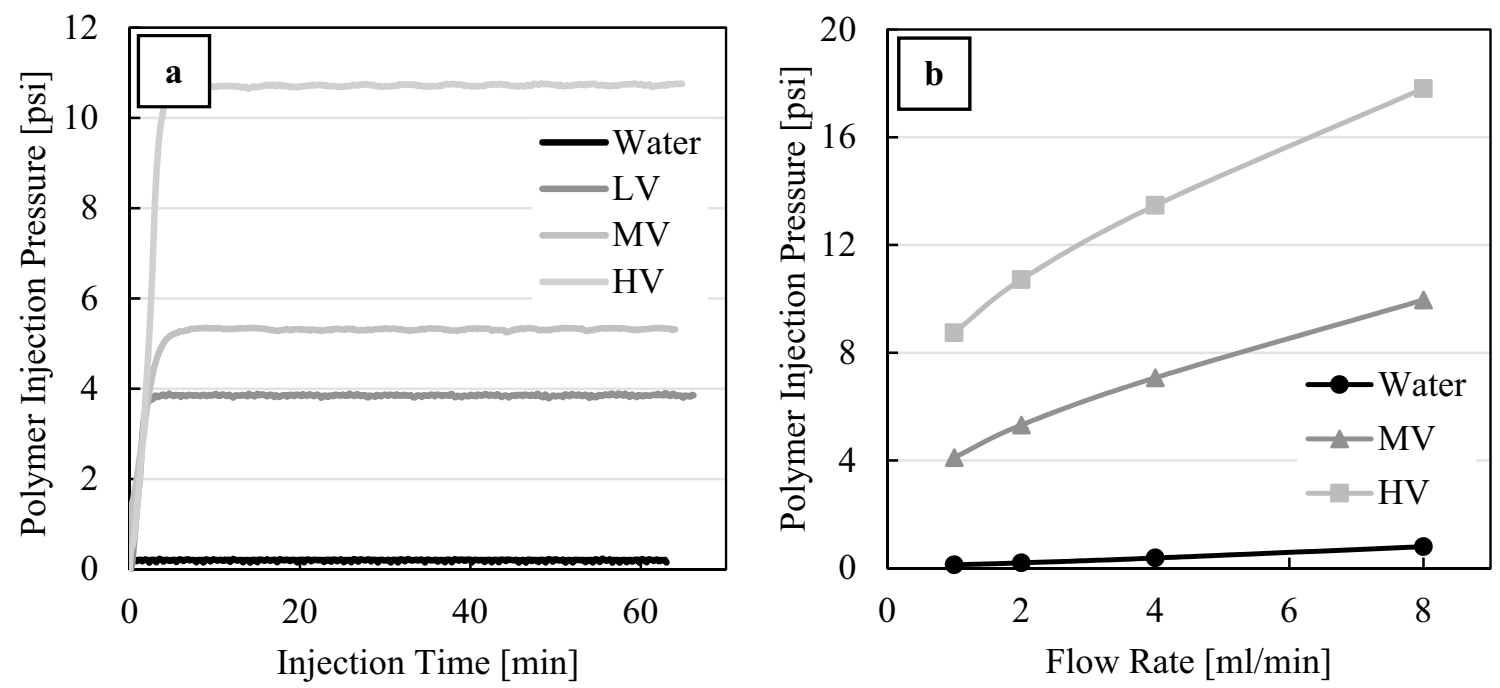

Fig. 7 Effect of the viscosity on the injectivity of the polymer solutions 
materials that can reduce the viscosity with minimum effects on mechanical properties, as reported in the literature.

\section{Effect of the viscosity of the fluid on the injectivity}

To understand whether the viscosity of the injection fluid had a major impact on the injectivity of the materials in the remedial jobs, three polymer solutions were injected into the same void size at the same flow rate $(2 \mathrm{ml} / \mathrm{min})$. The polymer solutions were HPAM with low viscosity (LV), HPAM with moderate viscosity (MV), and HPAM with high viscosity (HV). HPAM was selected because the rheological results of HPAM showed shear thinning behavior. The three HPAM solutions were injected into the smallest void size used in this study $(0.8763 \mathrm{~mm})$. Figure 7a shows the polymer injection pressure. Similar to the previous tests, the injection continued until a stable pressure was reached. In this case, the stabilized pressures for the LV, MV, and HV polymer solutions were around 3.9, 5.3, and 10.72 psi, respectively. These injection pressures were compared to that of water and the viscosity of the injection fluid played a major role in the injectivity of the material (see Fig. 7b), which shows the relationship between the injection pressure and the flow rate. Figure $7 \mathrm{~b}$ was generated using the same polymer solutions but different flow rates (i.e., 1, 2, 4, and $8 \mathrm{ml} / \mathrm{min}$ ). This relationship allowed for studying the combined effect of the flow rates and the viscosity on the injectivity of the materials. The relationship between the injection pressure and the flow rate for water is linear, unlike the relationship for the polymer solutions. Results similar to these should be considered in the field when sealants are applied. It is better for a successful sealant placement to employ a Newtonian fluid where the pressure at each flow rate can be predicted effectively. Additionally, it is beneficial that only a low or very small yield stress is required to initiate flow. It is noteworthy that the injectivity of the Newtonian fluid (water herein) did not change by changing the flow rate. This will be discussed further in the results of the epoxy resin injection.

\section{The effect of flow rate on injectivity}

For each material studied herein, flow rate experiments were conducted using multiple void sizes to study the effect of flow rate on the injectivity of the sealants. First, HPAM solutions were injected into the void. Figure $8 \mathrm{a}$ shows the results of injecting the moderate viscosity HPAM solution into a $0.8763 \mathrm{~mm}$ void. As can be seen, increasing the flow rate resulted in an increase in the injection pressure. The calculated injectivity associated with these measurements also showed an increase in the injectivity from $0.114 \mathrm{ml} /$ psi*min at a flow rate of $1 \mathrm{ml} / \mathrm{min}$ to $0.803 \mathrm{ml} / \mathrm{psi}$ *min at a flow rate of $8 \mathrm{ml} / \mathrm{min}$. Similar results were obtained when the low viscosity and high viscosity polymer solutions were injected. The results of changing the void size were also consistent with this behavior. However, the relationship between the stabilized injection pressure and the flow rate were not linear Fig. 8b, the opposite of the results obtained when water was injected.

The PPG showed similar results to those of the HPAM solutions, as shown in Fig. 9a but with the PPG, it was even more difficult to define a clear relationship between the injection pressure and the flow rates, as shown in Fig. $9 b$. These results further complicate the remedial operation. The behavior of the PPG is to the elasticity of this semisolid material. The gel particles deformed inside the void space, resulting in a high fluctuation in the pressure readings. The results presented here are for a void of $4.572 \mathrm{~mm}$, the largest size used in this study. For the smaller size $(1.753 \mathrm{~mm})$, the
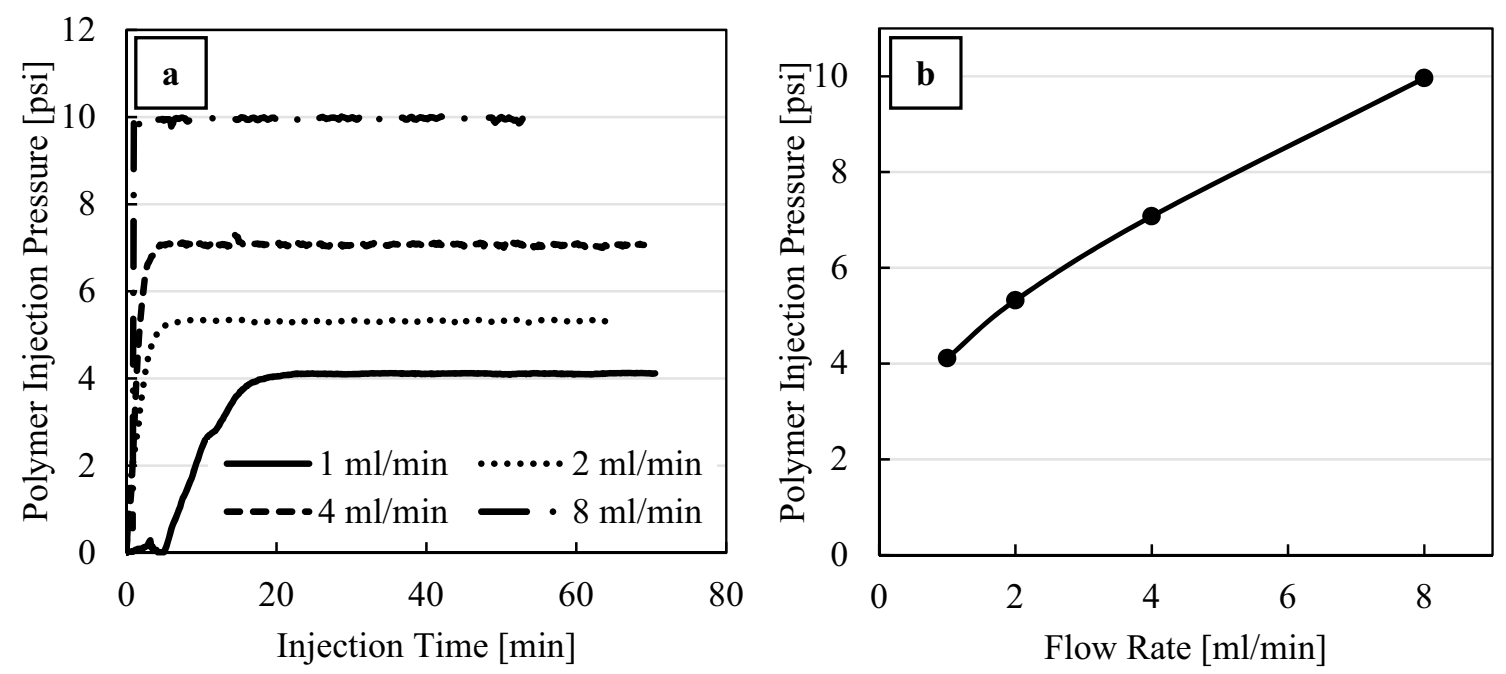

Fig. 8 Effect of the injection flow rate on the injectivity of the HPAM solution

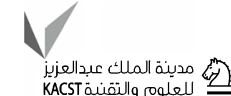



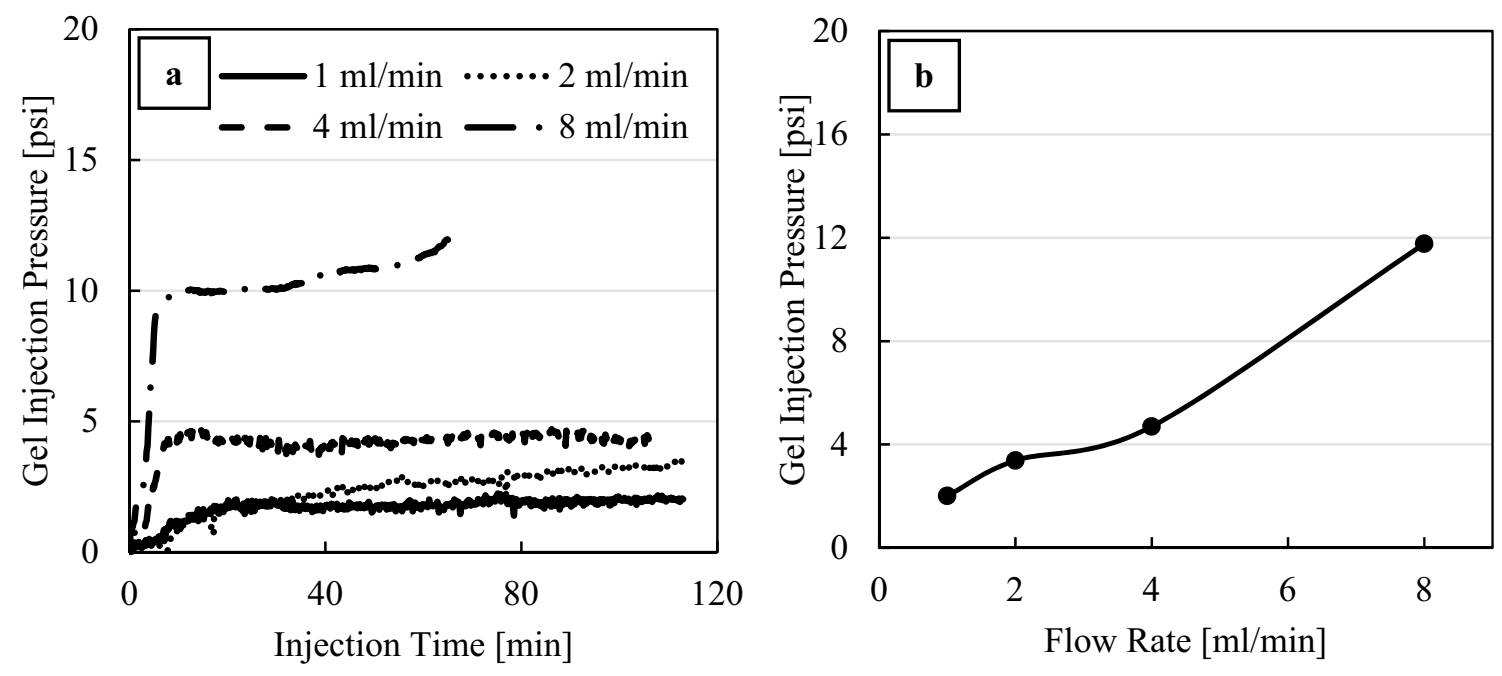

Fig. 9 Effect of the injection flow rate on the injectivity of the PPG
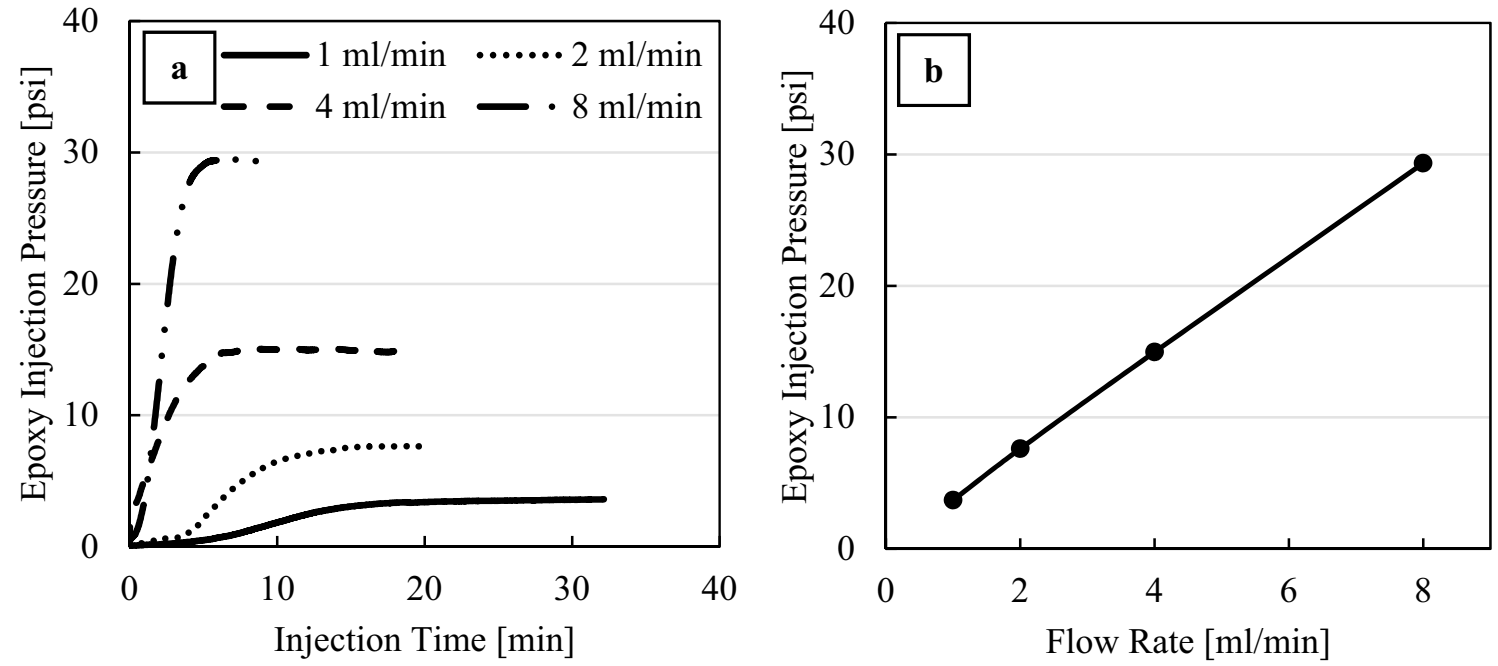

Fig. 10 Effect of the injection flow rate on the injectivity of the epoxy resin

results were even more complicated, and the gel particles left the void with permanent deformations. This might be solved using semisolid gel particles that can reassociate inside the void, creating an impermeable network capable of permanently plugging the cement features.

Epoxy, which is one of the most recent technologies in wellbore integrity, behaved differently. When the rheological properties of the epoxy resin were tested, it showed Newtonian behavior, which is the preferred behavior for this application in terms of the yield stress required to initiate movement. Figure 10a shows the results of injecting epoxy resin into a void size of $1.753 \mathrm{~mm}$, where increasing the flow rate of the injection resulted in an increase in the injection pressure. However, in this case the relationship between the injection pressure and the flow rate was linear, as shown in Fig. 10b.This is significant and advantageous because in this case, the injectivity was independent, and the injection pressure could be predicted precisely prior to any remedial job, leading to a placement with less risk of fracturing the cement and its surroundings, which would exacerbate the situation.

\section{Effect of heterogeneity on the injectivity}

The effect of the heterogeneity of the voids on the injectivity of the sealants in Figs. 11a, b, which show the injection pressure of the PPG and HPAM solutions, respectively. These figures show the pressure reading at various locations in the void. The solid-free material (HPAM) experienced no effect as a result of the heterogeneity, while 

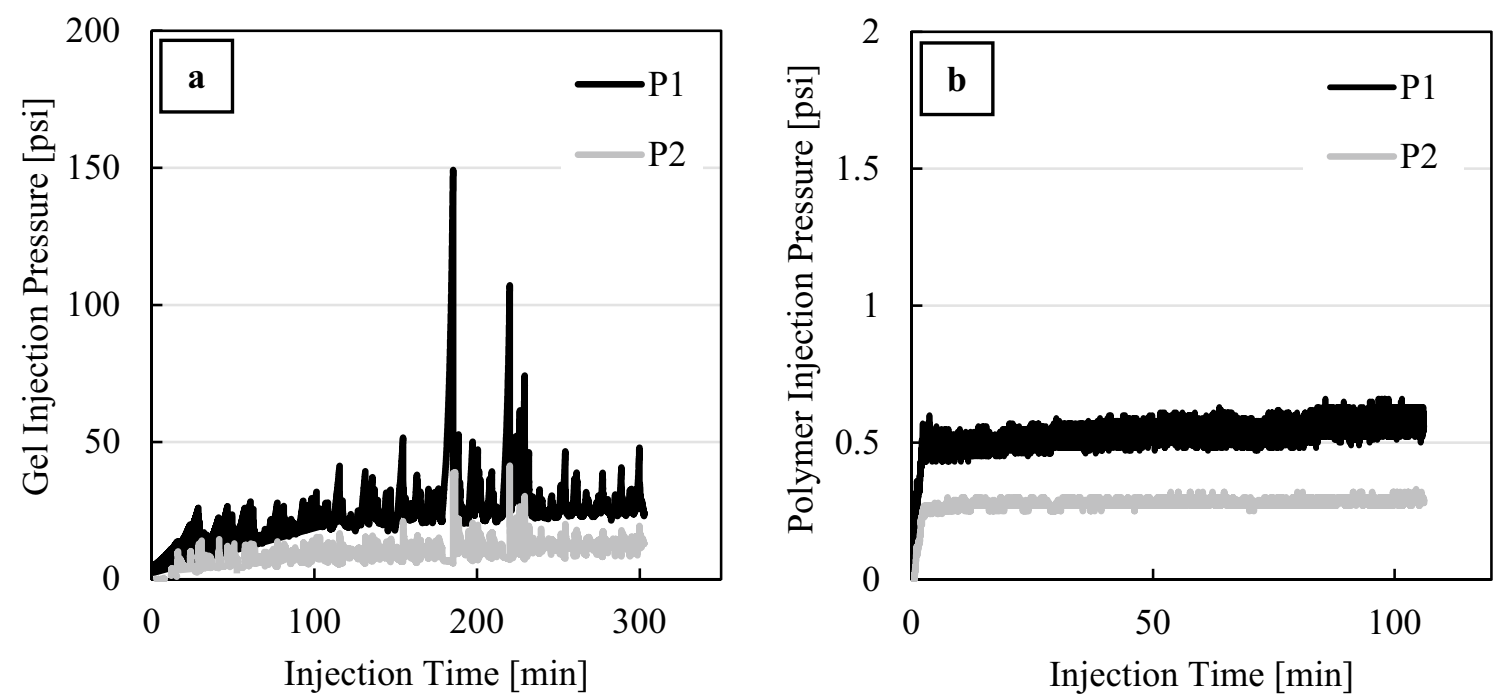

Fig. 11 Effect of the heterogeneity on the injectivity of the a PPG, and $\mathbf{b}$ HPAM solutions
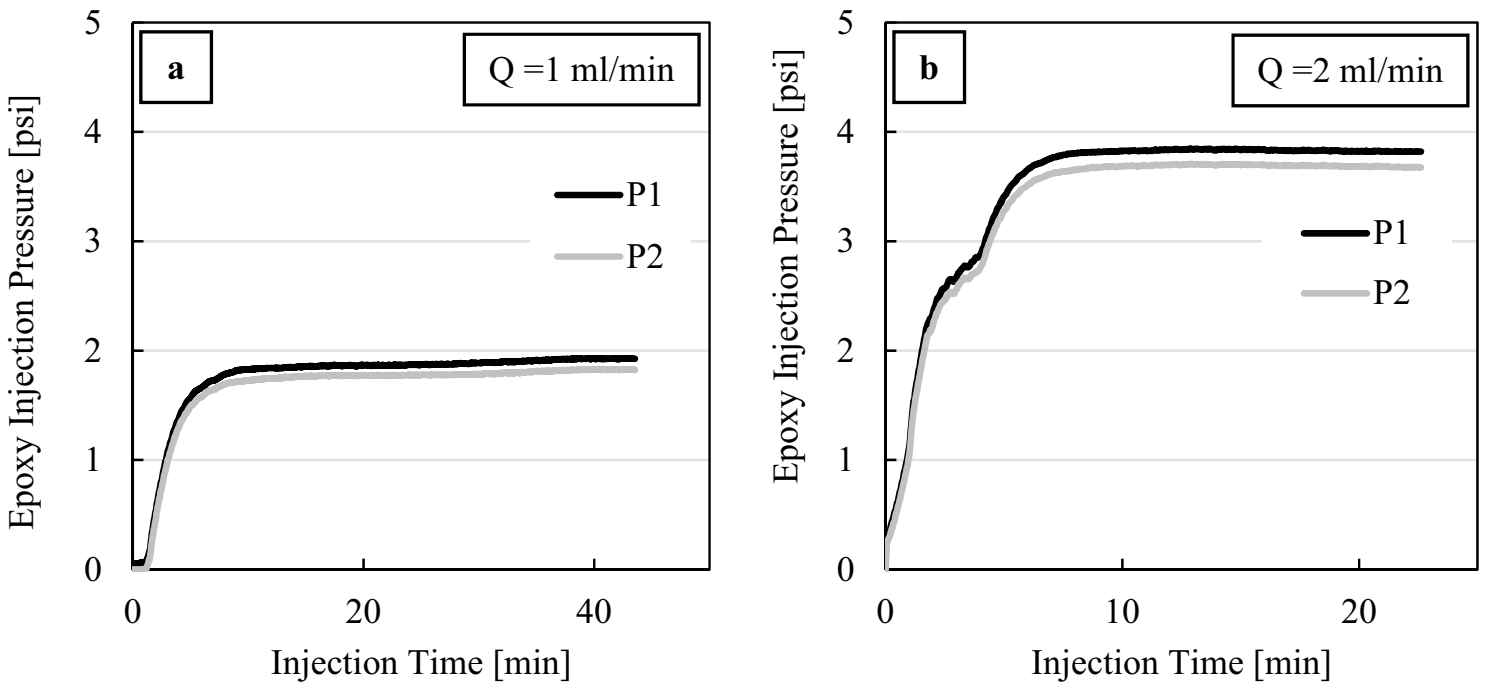

Fig. 12 Effect of the heterogeneity on the injectivity of the epoxy a $1 \mathrm{ml} / \mathrm{min}$, and b $2 \mathrm{ml} / \mathrm{min}$

the pressure reading for PPG rose and decreased and also reached higher values than those obtained using a uniform void of the same size. This suggests that using a solidsfree sealant reduces the risk of false readings during the placement of the sealant.

Figure 12a shows that epoxy sealants experiences minimum effect when injected into heterogenous void space. The pressure readings recorded at both the inlet and halfway of the void were close to each other, and the material was smoothly flowing in the void. Figure $12 \mathrm{~b}$ illustrates the effect of increasing the flow rate in a heterogenous void. Again, the epoxy flowed smoothly, and the pressure readings were close. The injectivity was slightly higher than that of the $1.753 \mathrm{~mm}$ void but lower than the $4.572 \mathrm{~mm}$ void. Additionally, the flow rate had very little effect on the injectivity.

Table 1 summarizes the results of the various sealant injectivities obtained at different flow rates, void sizes, and viscosity. Only Newtonian fluids showed the same injectivity when the flow rates varied.

\section{Rheology analysis after sealant injection}

Earlier, it was stated that the cement had undergone phase separation during and after the injection into the voids, which can affect the efficiency of the cement inside the cement gaps. In addition, we mentioned that a deformation 


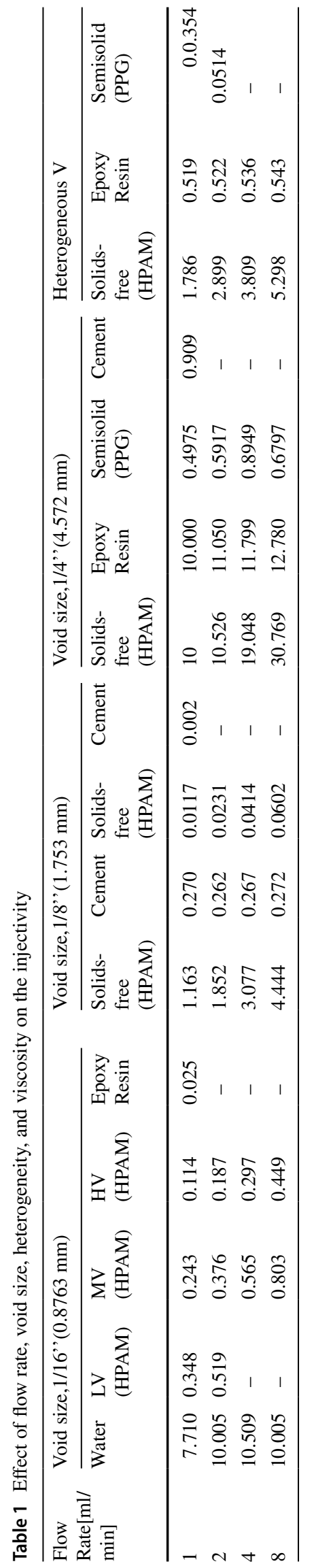

effect occurred when PPG was injected into the $1.753 \mathrm{~mm}$ voids, which might negatively affect the remedial operation. Conversely, the HPAM solutions and epoxy resin maintained their rheological behavior after injection. For the HPAM, the results of the rheology were almost identical before and after the injection, including injection at different flow rates. Figure 13a shows the rheology results of the HPAM solutions before the injection, while Fig. 13b displays the results directly after the injection. Figure 13 only presents the results of injecting the HPAM solutions into the smallest void $(0.8763 \mathrm{~mm})$. Similar results were obtained for the other flow rates using HPAM solutions Figs. 14a, b. These results are good indication and can wrap up the results of this study and a conclusion can be drawn that solids-free sealants such as epoxy resin might be the most effective solution for wellbore integrity applications.

Lastly, it is essential to show the solidification time of the epoxy resin used in this study. This type of sealant was used successfully in the field as addressed by (Alsaihati et al., 2017, and Elyas et al., 2018) but curing time of this sealant needed to be studied and especially the effect of temperature on the curing. The sealant at room temperature requires days to cure and the presence of heat is required as the curing agent used is aromatic amine, which requires elevated temperature to cure. Increasing the temperature reduced the curing time of the epoxy resin (see Fig. 15). At $80{ }^{\circ} \mathrm{C}$, the time required for the sealant to reach the gel point was approximately $18 \mathrm{~h}$, while at 100 ${ }^{\circ} \mathrm{C}$ was $7 \mathrm{~h}$.

\section{Conclusions}

This work presented the injectivity of several materials that can be used in the wellbore remediation of oil and gas wells. The effects of several factors were studied in detail, allowing several conclusions to be drawn. The main conclusions are summarized below:

- The void size, viscosity of the sealants, injection flow rates, and heterogeneity of the voids played major roles in determining the injectivity of the sealants. Having a sealant with Newtonian behavior was beneficial in eliminating the effect of the flow rate.

- Solids-free sealants exhibited the most potential to successfully remediate wellbores in terms of the injectivity of the material.

- Solids-free sealant demonstrated high injectivity and low degradation after injection. 

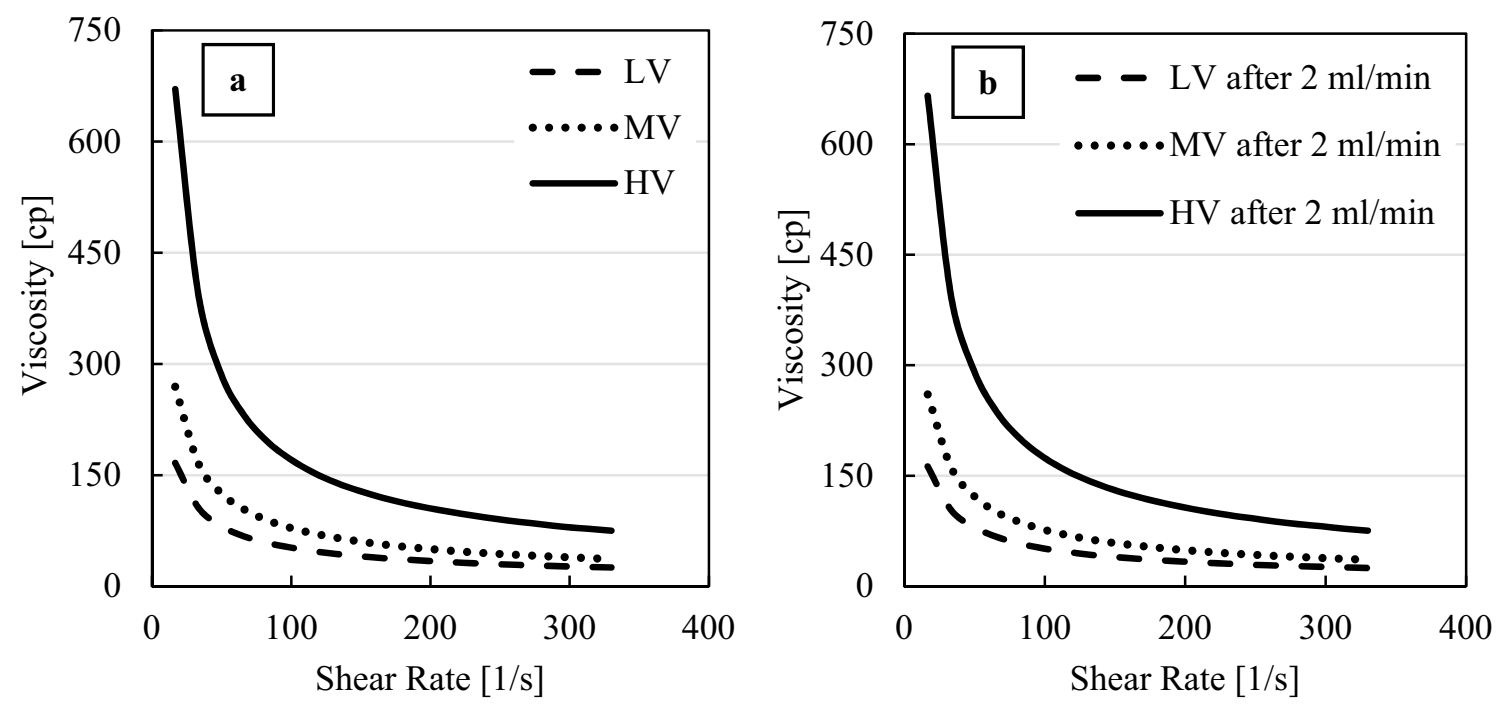

Fig. 13 Effect of the injection on the rheology of the HPAM solutions
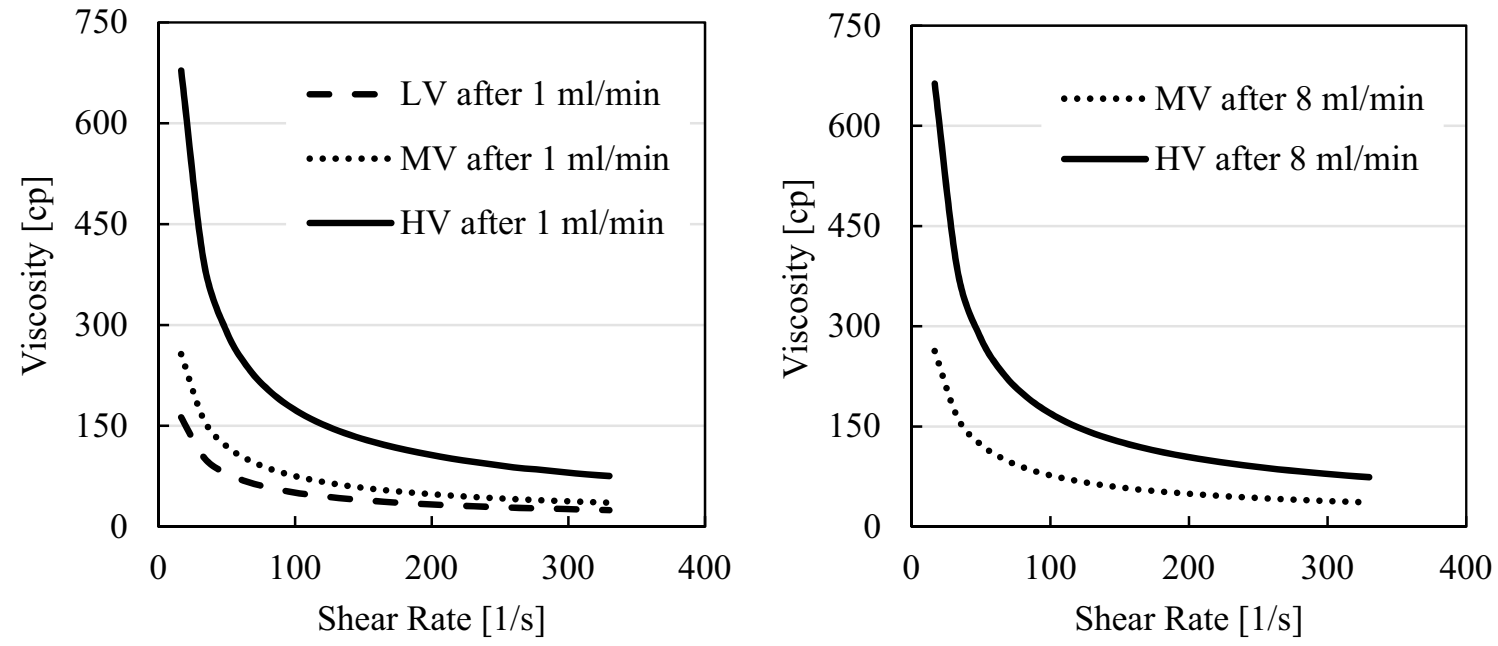

Fig. 14 Effect of the injection on the rheology of the HPAM solutions

- The epoxy resin showed Newtonian behavior, and the injectivity showed the effect that Newtonian materials have on the injectivity.

- The cement presented a huge limitation in terms of its ability to penetrate small voids.
- The PPG showed good injectivity, but unless this injectivity is correlated with the ability to develop enough strength to hold reservoir fluids in place, this injectivity is not useful. 
Fig. 15 The solidification time of the epoxy resin sealant as a function of time

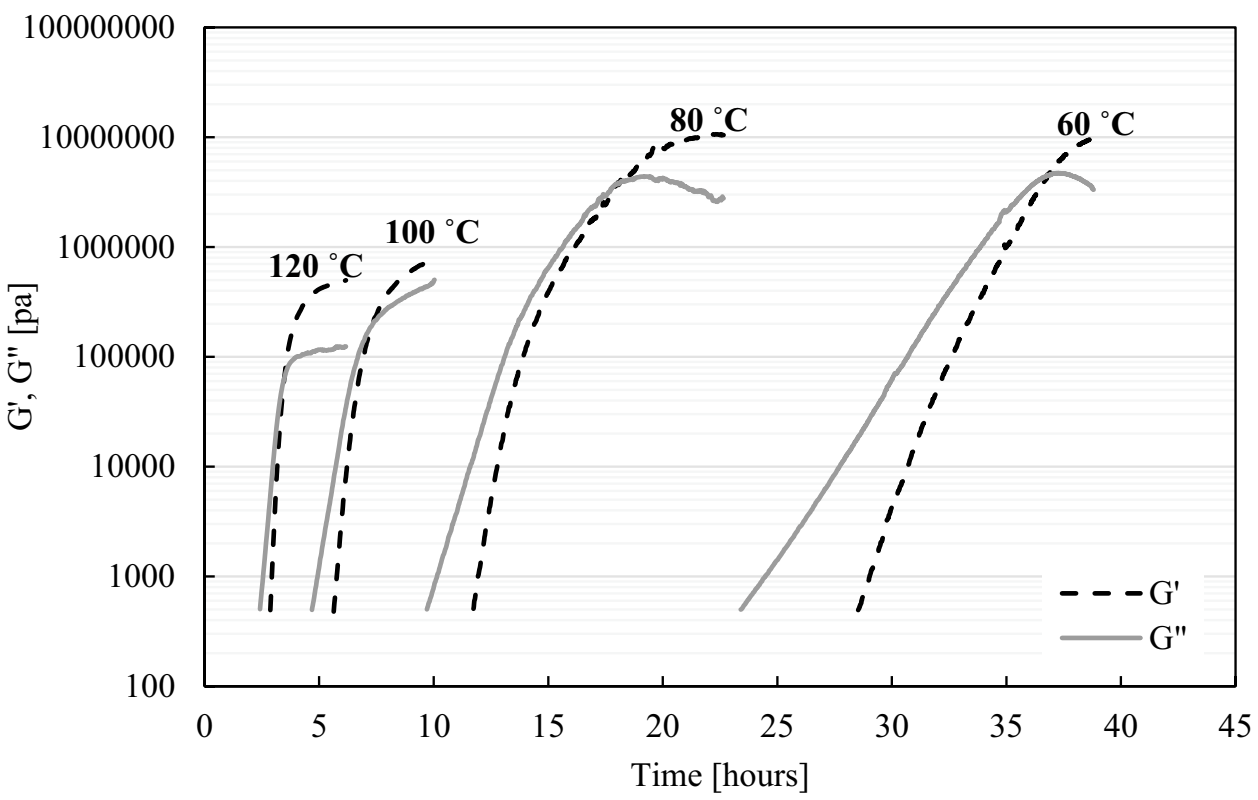

Acknowledgements The author wishes to thank the Saudi Arabian Cultural Mission (SACM) for their scholarship. In addition, the authors wish to thank Haliburton for their support by providing ClassH cement.

Funding The authors declare that there is no funding received to conduct this research.

\section{Declaration}

Conflict of interest On behalf of all the co-authors, the corresponding author states that there is no conflict of interest.

Open Access This article is licensed under a Creative Commons Attribution 4.0 International License, which permits use, sharing, adaptation, distribution and reproduction in any medium or format, as long as you give appropriate credit to the original author(s) and the source, provide a link to the Creative Commons licence, and indicate if changes were made. The images or other third party material in this article are included in the article's Creative Commons licence, unless indicated otherwise in a credit line to the material. If material is not included in the article's Creative Commons licence and your intended use is not permitted by statutory regulation or exceeds the permitted use, you will need to obtain permission directly from the copyright holder. To view a copy of this licence, visit http://creativecommons.org/licenses/by/4.0/.

\section{References}

Abdulfarraj M, Imqam A (2020) The potential of using micro-sized crosslinked polymer gel to remediate water leakage in cement sheaths. J Petrol Explor Prod Technol 10:871-881. https://doi. org/10.1007/s13202-019-00783-6

Ali A, Morsy A, Bhaisora D, Ahmed M (2016) Resin sealant system solved liner hanger assembly leakage and restored well integrity: case history from Western desert. Soc Petrol Eng. https:// doi.org/10.2118/183295-MS

Alkhamis M, Imqam A (2018) New cement formulations utilizing graphene nano platelets to improve cement properties and long-term reliability in oil wells. Soc Petrol Eng. https://doi. org/10.2118/192342-MS

Alkhamis M, Imqam A (2021) A simple classification of wellbore integrity problems related to fluids migration. Arab J Sci Eng. https://doi.org/10.1007/s13369-021-05359-3

Alkhamis, Mohammed , Imqam, Abdulmohsin, Muhend Milad. (2019) Evaluation of an ultra-high performance epoxy resin sealant for wellbore integrity applications. Paper presented at the SPE Symposium: Decommissioning and Abandonment, Kuala Lumpur, Malaysia, doi: https://doi.org/10.2118/ 199184-MS.

Alsaihati ZA, Al-Yami AS, Wagle V, BinAli A, Mukherjee TS, AlKubaisi A, Alsafran A (2017) An overview of polymer resin systems deployed for remedial operations in Saudi Arabia. Soc Petro Eng. https://doi.org/10.2118/188122-MS

Brooks FA, Muecke TW, Rickey WP, Kerver JK (1974) Externally catalyzed epoxy for sand control. Soc Petrol Eng. https://doi.org/ 10.2118/4034-PA

Dahlem JE, Baughman T, James T, Kelly Rives R (2017) Intervention and abandonment - riserless productive zone abandonment using epoxy resin. Offshore Technol Conf. https://doi.org/10.4043/ 27847-MS

Davis JE (2017) Using a resin-only solution to complete a permanent abandonment operation in the gulf of Mexico. Soc Petrol Eng. https://doi.org/10.2118/186113-MS

Elyas O, Alyami A, Wagle V, Alhareth N (2018) Use of polymer resins for surface annulus isolation enhancement. Soc Petrol Eng. https:// doi.org/10.2118/192266-MS

Genedy M, Kandil UF, Matteo EN, Stormont J, Reda MM, Taha, (2017) A new polymer nanocomposite repair material for restoring wellbore seal integrity, International. J Greenhouse Gas Cont 58:290-298. https://doi.org/10.1016/j.ijggc.2016.10.006

Imqam A, Wang Z, Bai B (2017) Preformed-particle-gel transport through heterogeneous void-space conduits. Soc Petrol Eng. https://doi.org/10.2118/179705-PA

Jones PJ, Karcher J, Ruch A, Beamer A, Smit P, Hines S, Day D (2014) Rigless operation to restore wellbore integrity using syntheticbased resin sealants. Soc Petrol Eng. https://doi.org/10.2118/ 167759-MS

Khanna M, Sarma P, Chandak K, Agarwal A, Kumar A, Gillies J (2018) Unlocking the economic potential of a mature field through

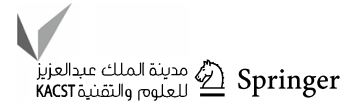


rigless remediation of microchannels in a cement packer using epoxy resin and ultrafine cement technology to access new oil reserves. Soc Petrol Eng. https://doi.org/10.2118/189350-MS

London B, Tennison B, Karcher J, Jones P (2013) Unconventional remediation in the utica shale using advanced resin technologies. Soc Petrol Eng. https://doi.org/10.2118/165699-MS

Morris K, Deville JP, Jones P (2012) Resin-based cement alternatives for deepwater well construction. Soc Petrol Eng. https://doi.org/ 10.2118/155613-MS

Muecke TW (1974) Factors influencing the deterioration of s plastic sand consolidation treatments. Soc Petrol Eng. https://doi.org/10. 2118/4354-PA

NORSOK D-010. NOSOK D-010 Rev.4. (2013). Well integrity in drilling and well operations. Standard Norway.

Perez V, Miguel M, Jardyson B, Romulo R, Andre PJ (2017) Epoxy resin helps restore well integrity in offshore well: case history. Paper presented at the OTC Brasil, Rio de Janeiro, Brazil https:// doi.org/10.4043/28124-MS

Sanabria AE, Knudsen K, Leon GA (2016) Thermal activated resin to repair casing leaks in the middle east. Soc Petrol Eng. https://doi. org/10.2118/182978-MS

Shaughnessy CM, Salathiel WM, Penberthy WL (1978) A new soc petrol eng low-viscosity epoxy sand-consolidation process. Soc Petrol Eng. https://doi.org/10.2118/6803-PA
Shryock SH, Slagle KA (1968) Problems related to squeeze cementing. Soc Petrol Eng. https://doi.org/10.2118/1993-PA

API Specification 10A/ISO 10426-1, Specification for Cements and Materials for Well Cementing, Twenty-third Edition

Thiercelin MJ, Dargaud B, Baret JF, Rodriquez WJ (1998) Cement design based on cement mechanical response. Soc Petrol Eng. https://doi.org/10.2118/52890-PA

Todd L, Cleveland M, Docherty K, Reid J, Cowan K, Yohe C (2018) Big problem-small solution: nanotechnology-based sealing fluid. Soc Petrol Eng. https://doi.org/10.2118/191577-MS

Vicente Perez M, Melo J, Blanc R, Roncete A, Jones P (2017) Epoxy resin helps restore well integrity in offshore well: case history. Paper presented at the OTC Brasil Rio de Janeiro, Brazil https:// doi.org/10.4043/28124-MS

API RP 10B-2, Recommended practice for testing well cements, second edition. 2012. Washington, DC: API.

Wasnik AS, Mete SV, Ghosh B (2005) Application of resin system for sand consolidation, mud loss control \& channel repairing. Soc Petrol Eng. https://doi.org/10.2118/97771-MS 